\title{
Cantons de Saint-Affrique et Saint-Rome-de-Tarn
}

\section{(2) OpenEdition \\ Journals}

Édition électronique

URL : http://journals.openedition.org/adlfi/11088

ISSN : 2114-0502

Éditeur

Ministère de la culture

Référence électronique

"Cantons de Saint-Affrique et Saint-Rome-de-Tarn », ADLFI. Archéologie de la France - Informations [En ligne], Midi-Pyrénées, mis en ligne le 01 mars 1997, consulté le 03 mai 2019. URL : http://

journals.openedition.org/adlfi/11088

Ce document a été généré automatiquement le 3 mai 2019.

(C) Ministère de la Culture et de la Communication, CNRS 


\section{Cantons de Saint-Affrique et Saint- Rome-de-Tarn}

Date de l'opération : 1991 (PI)

Inventeur(s) : Pons Fabrice

1 Suite au décès de P. Cabane, qui a longuement prospecté la région de Saint-Affrique, réunissant ainsi la plus importante collection sur ce secteur partagé entre les bassins permo-triasiques et les Avant-Causses du sud de l'Aveyron, l'inventaire archéologique qu'il avait commencé a été repris et complété par Jean Poujol. Par ailleurs, Fabrice Pons a été chargé de vérifier sur le terrain les données en fonction des normes de la carte archéologique nationale. Ces vérifications achevées permettront de développer une synthèse sur le peuplement paléolithique de la région de Saint-Affrique.

2 Pour la Préhistoire et la Protohistoire ancienne, les découvertes consistent essentiellement en stations attribuables, d'une part, au Paléolithique moyen (station principale: Fontbouillenc), d'autre part, aux mégalithes et stations de surface du Néolithique récent/Chalcolithique : Les Costes-Gozon, Puech Ballier et combe du Rouquet à Gissac, etc.

3 Les gisements paléolithiques, tous en plein air, sont établis sur des plateaux calcaires liasiques pour lesquels une exploitation de la chaille, calcaire siliceux local, domine dans les assemblages lithiques. Le quartz intervient comme matériau complémentaire. Plus d'une dizaine de stations ont été recensées. D'après une étude sommaire des nucléus de Fontbouillenc (types Levallois et discoïdes) et des principaux produits (éclats Levallois, pointes pseudo-Levallois), le débitage Levallois semble presque exclusif sur chaille, correspondant à une modalité de type Levallois récurrent centripète. Une association entre la production Levallois principale et un débitage de type discoïde est cependant possible.

4 Sur un plan technotypologique, les séries moustériennes du bassin de Saint-Affrique rappellent celles décrites par Liliane Meignen pour l'abri voisin des Canalettes (infra), indiquant, selon nous, une homogénéité régionale évidente pour le sud de l'Aveyron. 
INDEX

peuple Moustérien

Index chronologique : Paléolithique moyen

operation Prospection inventaire (PI) 